\title{
Response to "Lack of association between bovine leukemia virus and breast cancer in Chinese patients"
}

\author{
Gertrude Case Buehring
}

See related Letter by Zhang et al. 10.1186/s13058-016-0763-8

We are pleased that our publication [1] inspired the authors to investigate the relationship of bovine leukemia virus (BLV) and breast cancer in Chinese women. However, aspects of the methodology presented cast doubt on the accuracy of the results. The authors state (third paragraph) "Similarly, the commercial ELISA kit used in our study could readily detect BLV-specific antibodies in all cows which were also positive for BLV by PCR, but failed to detect reactive antibodies in Chinese women with or without breast cancer." Six commercial BLV antibody testing kits are available for veterinary use from the following companies: VMRD, IDEXX, Svanova, Zoetis, Demeditec, and Biovet. Zhang et al. used a kit from BioVet (personal communication with one of the authors). The commercial kits were intended for cattle and were standardized and extensively tested for the level of anti-BLV antibody usually found in BLV-infected cattle, which is much higher than that found in humans [2,3]. Therefore, it would be unlikely that the veterinary kits would detect the lower level of human anti-BLV antibody that we were able to detect only with immunblotting, and not by ELISA [3]. The commercial kits are not intended for testing human sera; some would be negative for all human sera because the final detection step involves a labeled antibody to bovine, not human, immunoglobulin. Kit directions explicitly say "for veterinary use only" or "intended for detection of BLV antibodies in cattle serum and milk."

In addition, the PCR methodology is difficult to evaluate. The second paragraph states "In this study, we conducted seven PCRs according to Buehring's group [3, 4] and one published real-time PCR." Our reported research $[1,4]$ used in situ PCR, which requires sample preparation, cycling times/temperatures, reaction mix composition, and

Correspondence: buehring@berkeley.edu

Division of Infectious Diseases and Vaccinology, School of Public Health, University of California, 16 Barker Hall, Berkeley, CA 94720-7354, USA a thermal cycler different from those used for standard solution PCR and real-time PCR. It is impossible from the information given to evaluate whether the authors' in situ PCR techniques were equivalent to what we used. Understandably, the authors were probably confined by the journal's word limit for a "Letter" and could not give additional information.

It is plausible that the reported lack of detectable BLV infection in Chinese women with breast cancer could relate to lower consumption of bovine food products in China compared to the USA. However, this conclusion cannot be firmly made based on the methodology presented in this publication; further research on this topic is needed.

\section{Abbreviations}

BLV: Bovine leukemia virus; ELISA: Enzyme-linked immunosorbent assay; PCR: Polymerase chain reaction

\section{Acknowledgements}

Acknowledgements are given below to authors of reference [1] who reviewed this Letter manuscript and some of whom suggested slight revisions. They declined the offer of co-authorship on the basis that their only contribution was a review of the manuscript.

\section{Funding}

The content of this submission was not funded. The author currently has no grant funding

\section{Availability of data and materials}

No supporting data are associated with this submission. It is not an original research article.

\footnotetext{
Authors' contributions

The sole author of this Letter, Gertrude Buehring, identified on the Internet the current sources of diagnostic kits for bovine leukemia virus, reviewed for each of those kits the product description sheets describing the methodology used and the scientific basis of that methodology, and personally contacted by phone the technical support staff of several of these companies to confirm that the kits were inappropriate for detecting human antibodies to bovine leukemia virus. She also communicated with the corresponding author of the manuscript being commented on (Zhang et al.) to confirm which of the available diagnostic kits was used for their antibody analyses.
} 


\section{Competing interests}

My interest in writing this Letter of response could be considered a competing interest, but I think of it more as important education for other scientists. Zhang et al. reported no evidence of bovine leukemia virus in human breast tissue or of antibodies to bovine leukemia in the serum of humans, which is contradictory to our previous findings (references [1-4]). However, their use of a veterinary antibody assay kit for humans is inappropriate, for reasons described in the commentary, and their negative results could send the wrong message to other researchers that the available veterinary diagnostic kits are appropriate for human use, which is not the case. Their PCR methods are not described adequately enough to fully evaluate.

\section{Consent for publication}

No other authors were involved in this Letter submission.

\section{Ethics approval and consent to participate}

This is not applicable to this Letter, which is not reporting any original research, but rather comments on research previously reported in Breast Cancer Research. No human or animal subjects were involved in the preparation of this Letter.

\section{Received: 2 December 2016 Accepted: 27 January 2017}

Published online: 07 March 2017

\section{References}

1. Buehring GC, Shen HM, Jensen HM, Jin DL, Hudes M, Block G. Exposure to bovine leukemia virus is associated with breast cancer: a case-control study. PLoS One. 2015;10(9):e0134304.

2. Choi KY, Liu RB, Buehring GC. Relative sensitivity and specificity of agar gel immunodiffusion, enzyme immunosorbent assay, and immunoblotting for detection of anti-bovine leukemia virus antibodies in cattle. J Virological Methods. 2002;104:33-9.

3. Buehring GC, Philpott SM, Choi Y. Humans have antibodies reactive with bovine leukemia virus. AIDS ResHuman Retroviruses. 2003;19:1105-13.

4. Buehring GC, Shen HM, Jensen HM, Choi KY, Sun D, Nuovo G. Bovine leukemia virus DNA in human breast tissue. Emerg Infect Dis. 2014;20:772-82. 